\title{
Patrimonio cultural oscuro como recurso para el diseño y comercialización de experiencias turísticas
}

\author{
Andrés Sánchez-Clemente Ramos | Proyectos Culturales \\ URL de la contribución <www.iaph.es/revistaph/index.php/revistaph/article/view/5043>
}

Con la reciente, y necesaria, revisión de la definición de patrimonio cultural se han ampliado los límites del mismo. Esta ampliación conlleva reconocer el valor social que implica. Pero no es nuevo que las personas y los valores humanos sean (o deban ser) el centro de toda acción en patrimonio cultural: en la Convención de Faro, celebrada en 2005 en la ciudad homónima, se subrayó la importancia del patrimonio cultural para la sociedad. En este encuentro se declaró que el patrimonio cultural posee el potencial suficiente para convertirse en un recurso clave para el desarrollo sostenible capaz de mejorar la vida de todas las personas. Una década después, en septiembre de 2015, 193 miembros de las Naciones Unidas dieron forma al programa global más ambicioso que jamás se había planteado en materia de desarrollo sostenible: 17 objetivos de desarrollo sostenible y 169 metas para su consecución. Estos objetivos, también conocidos como ODS, exigen un equilibrio entre las tres dimensiones que contemplan: medioambiental, social y económica.

El patrimonio cultural tiene un papel fundamental en los objetivos de desarrollo sostenible, particularmente en la dimensión social: el patrimonio cultural es aquello que, como sociedad, decidimos proteger y transmitir a futuras generaciones. El patrimonio cultural es un concepto social (...) cambiante (Ateca Amestoy et ál. 2020 , 9). Por estos motivos han surgido numerosos patrimonios culturales específicos como respuesta y adaptación del patrimonio cultural a la demanda social de valorización de aquellos elementos que conforman nuestra identidad. Es en este marco en el que reconocemos el nuevo patrimonio cultural específico denominado oscuro. No obstante, cabe recordar que la división entre tipos específicos del patrimonio cultural (...) está basada en las especialidades profesionales que lo tratan (Querol 2010, 29).

El patrimonio cultural oscuro es aquel que incorpora atributos tangibles e intangibles asociados a sucesos traumáticos. Y es la unión de estas dimensiones, la tangible y la intangible, lo que caracteriza a este patrimonio cultural específico. Como atributos tangibles destacan espacios y lugares, edificaciones e infraestructuras, útiles y enseres personales o documentos. Como atributos intangibles se emplea la memoria o el recuerdo. $Y$ son estos atributos la "materia prima" con la que se diseñan y comercializan productos turísticos: un producto está constituido por un conjunto de atributos, tanto tangibles como intangibles (Rico García y Sacristán Navarro 2017, 224). No obstante un producto o servicio turístico no es una experiencia turística en sí (aunque se comercialice bajo esta denominación). Una experiencia turística apela a las emociones, evoca sentimientos, en muchos casos encontrados, y transforma un producto o servicio turístico en algo memorable. Al igual que en patrimonio cultural son necesarias las clasificaciones, en turismo también se precisan. Son muchas las modalidades de turismo existentes: de sol y playa, cultural, de naturaleza, gastronómico, de negocios, de salud... y, por supuesto, turismo negro. La denominación formal de esta modalidad es tanatoturismo, es decir turismo asociado a la muerte (del griego thánatos, muerte).

El interés por atracciones asociadas al sufrimiento y al dolor no es nuevo. No obstante, como fenómeno turístico, sí es reciente. De hecho, es a finales del siglo $\mathrm{XX}$ cuando se comienza a emplear el término turismo oscuro. Desde ese momento los atributos, tangibles e intangibles, asociados a la muerte se conceptualizaron 


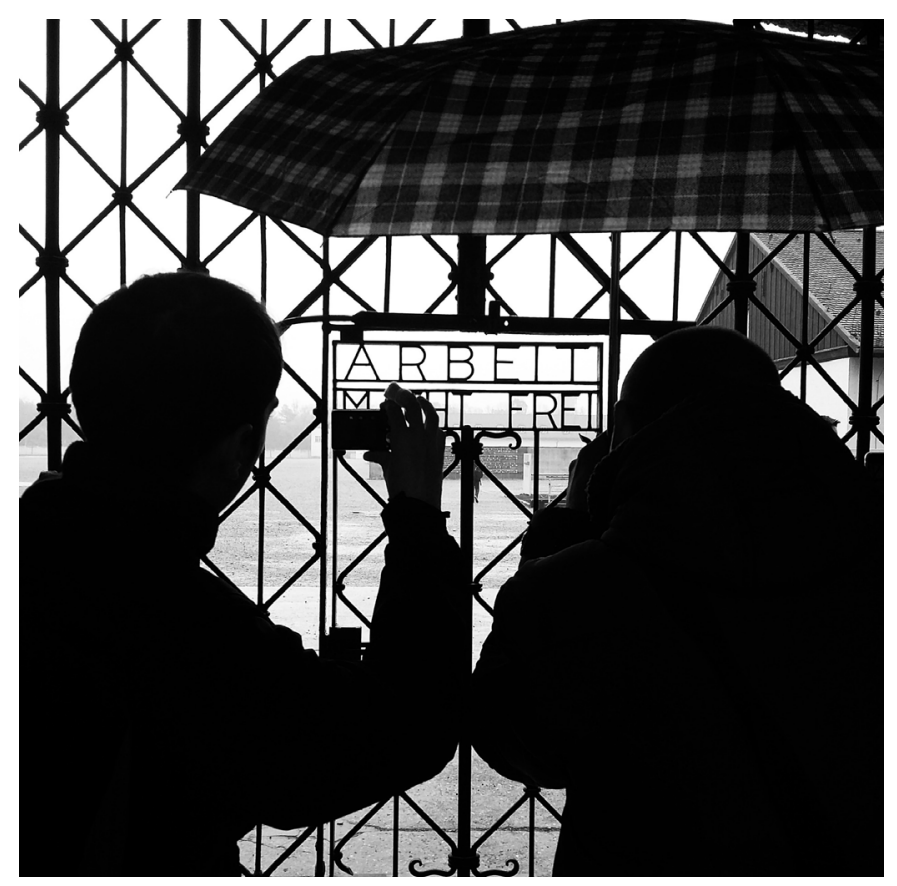

Visita al campo de concentración de Dachau | foto pixabay

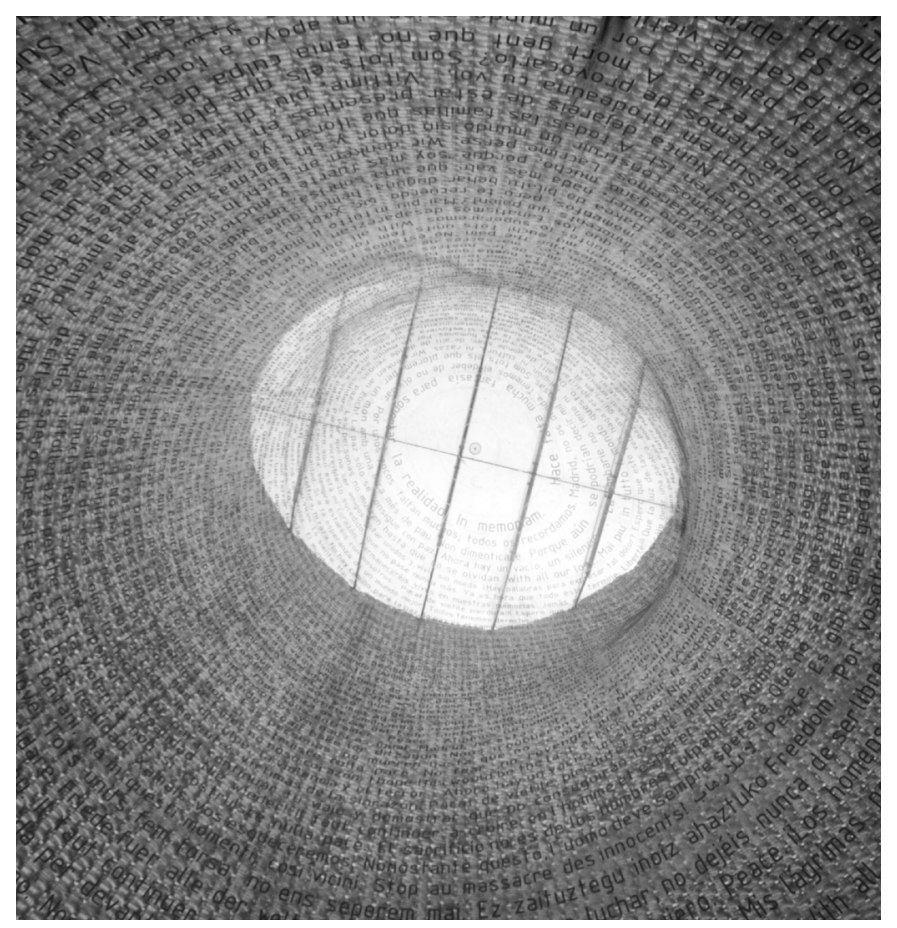

Interior del monumento a las víctimas de los atentados del $11 \mathrm{M}$ en Madrid | foto Fermín R.F. como recursos para el diseño y comercialización de productos y servicios turísticos.

Atendiendo al diseño de un producto turístico, este cuenta con cuatro niveles. El primero es el beneficio central del producto y se corresponde con la necesidad básica que desea satisfacer la persona que lo consume (cabe recordar que el turista no compra productos, sino los beneficios asociados al mismo). El segundo nivel es el producto auxiliar: en este nivel se encuentran los bienes y servicios esperados por el cliente para disfrutar del beneficio central. El tercer nivel es el producto de apoyo: este nivel de producto se presenta como un extra, es decir, complementos que mejoran la experiencia del cliente o usuario. El cuarto, y último nivel, es el producto aumentado: este nivel hace referencia al conjunto de mejoras que agregan valor al producto turístico. Es en este nivel donde se produce la transformación de producto o servicio a experiencia turística.

El tanatoturismo no es ajeno a este modelo de diseño de experiencias. Y por ello, emplea todos los recursos asociados a la muerte disponibles para captar el interés del público. Basta con realizar una búsqueda en internet sobre tanatoturismo para obtener numerosa información al respecto $y$, además, cuantiosas propuestas comerciales para visitar la zona cero de los atentados del 11-s, la central nuclear de Chernóbil, los campos de la muerte en Camboya o los campos de concentración nazis. El tanatoturismo es una realidad, se ofrecen y se demandan este tipo de experiencias: hay mercado.

El consumo de un producto o servicio determina su producción o entrega. Atendiendo al tanatoturismo, la oferta debe satisfacer la motivación de visitar espacios y lugares asociados a la muerte aunque, inexorablemente, cuente con un carácter siniestro. Pero no es la siniestralidad de estas propuestas lo que genera debate (incluso discusión), es el tratamiento: su comercialización e interpretación. Para satisfacer una demanda social de experiencias insólitas ¿cuáles son los límites, si existen, en la comercialización e interpretación del patrimonio cultural oscuro? 
Por una parte, la comercialización de un producto o servicio, sea de la naturaleza que sea, pretende emplear los recursos disponibles de forma eficaz y eficiente. Por otra, el objetivo de la interpretación del patrimonio, según el cuarto principio de Tilden, no es la instrucción, sino la provocación. Ante esta situación, disposición hacia el máximo rendimiento y búsqueda de la provocación, el tratamiento de este patrimonio cultural específico se presenta complejo.

Como ejemplo de esta complejidad cabe reseñar el reciente caso de intento de subasta de troqueles empleados en Auschwitz por nazis para identificar a los presos del campo de concentración: legalmente la transacción era viable en Israel (la casa de subastas se asesoró previamente para no cometer ninguna transgresión), moralmente la venta fue reprobada, obligando así a detener las pujas. El subastador, nieto de superviviente de campo de concentración nazi, alegó ser el primer interesado en que los objetos llegasen al propietario adecuado y nunca pretendió negar el valor del recuerdo de las víctimas.

Ante esta real oferta y demanda (transacción) de objetos o experiencias insólitas se presenta un desafío que involucra al patrimonio cultural, especialmente en lo referente a su gestión. Es indudable que el tratamiento que se haga debe ser adecuado a la naturaleza de los recursos empleados. Pero no por ello se deben desdeñar estrategias que, contemplado unos límites, favorezcan su viabilidad y sostenibilidad. Determinar estos límites es el reto que se nos plantea al sector patrimonial asumiendo que estos límites no son estáticos, si no dinámicos como el propio concepto de patrimonio cultural.

\section{BIBLIOGRAFÍA}

- Ateca Amestoy, V., Buey Cieslak, V., Stanojev, J. y Velasco Rebollo, A.I. (2020) Desafíos y oportunidades globales en el ámbito del patrimonio cultural. Heritage-pro Programa de capacitación, Módulo de formación 1. Erasmus+ Programe, European Union. Disponible en: https://heritage-pro.eu/wp-
content/uploads/2020/07/HERITAGE PRO Module-1-ES.pdf [Consulta: 16/11/2021]

- Emergi, S. (2021) Suspendida la subasta de una máquina de tatuaje usada por los nazis en Auschwitz. El Mundo, 5 noviembre 2021. Disponible en: https://www.elmundo.es/ internacional/2021/11/05/6185100dfc6c83ba728b45c2.html [Consulta: 12/11/2021]

- Querol, M.A. (2010) Manual de gestión del Patrimonio Cultural. Madrid: Akal

- Rico García, M.G. y Sacristán Navarro, M. (2017) Fundamentos empresariales. Madrid: ESIC 